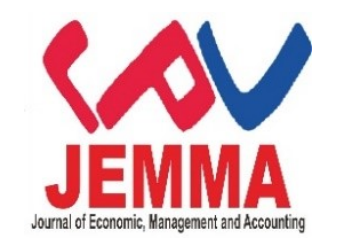

JEMMA | JURNAL OF ECONOMIC, MANAGEMENT AND ACCOUNTING

Fakultas Ekonomi Universitas Andi Djemma

Jl. Puang H. Daud No 4 Kota Palopo, Email: jemma.unanda@gmail.com

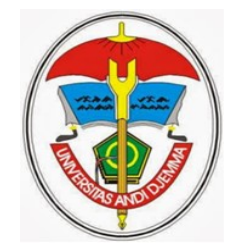

\section{PENGARUH REWARD DAN PUNISHMENT TERHADAP KINERJA KARYAWAN PADA KSP BALOTA KOTA PALOPO}

Info Artikel

Penulis

${ }^{1}$ Amri

${ }^{1}$ Prodi Manajemen FE. Unanda

Email : Amriunanda09@gmail.com
p-ISSN : 2615-1871

e-ISSN : 2615-5850

Volume 2 Nomor 2, September 2019

Received 25th July 2019 / Accepted 31th August 2019

\begin{abstract}
ABSTRAK
Penelitian ini bertujuan untuk mengetahui bagaimana pengaruh Reward dan Punishment terhadap kinerja karyawan pada KSP BALOTA Kota Palopo. Sampel dalam penelitian ini sebanyak 20. Teknik pengumpulan data menggunakan observasi, wawancara dan kuesioner. Aalat analisis data yang digunakan yaitu dengan menggunakan regresi linear berganda. Dari hasil penelitian menunjukkan bahwa Reward dan Punishment secara bersama-sama berpengaruh terhadap kinerja karyawan pada KSP BALOTA Kota Palopo. Secara parsial reward berpengaruh positif dan signifikan terhadap kinerja karyawan pada KSP BALOTA Kota Palopo dan Punishment berpengaruh positif dan signifikan terhadap kinerja karyawan pada KSP BALOTA Kota Palopo. Semakin baik penerapan Reward dan Punishment pada KSP BALOTA Kota Palopo maka akan semakin meningkatkan kinerja karyawan.
\end{abstract}

Kata Kunci: Reward, Punishment, Kinerja Karyawan

\title{
PENDAHULUAN
}

Ketersediaan akses yang mudah, memadai, dan berkelanjutan terhadap jasa dan produk keuangan, lembaga keuangan formal berperan penting dalam kelangsungan keberadaan dan pertumbuhan puluhan juta unit usaha di Indonesia. Saat ini beragam lembaga formal yang menyediakan jasa keuangan mikro beroperasi di Indonesia dan secara aktif melayani kebutuhan keuangan rumah tangga serta usaha berskala mikro kecil di Indonesia. Salah satu bagian dari kelompok lembaga formal tersebut adalah lembaga koperasi yang dapat berbentuk Koperasi Simpan Pinjam (KSP) atau unit simpan pinjam. (Sitorus, 2013). Koperasi Simpan Pinjam (KSP) adalah lembaga keuangan bukan bank yang berbentuk koperasi dengan kegiatan usaha menerima simpanan dan memberikan pinjaman uang kepada para anggotanya dengan bunga yang serendah-rendahnya.Koperasi simpan pinjam atau biasa disebut koperasi kredit merupakan salah satu bentuk koperasi yang berdiri sendiri dimana anggota-anggotanya adalah orang-orang atau badan-badan yang tergabung dalam koperasi tersebut. Mereka yang tidak terdaftar sebagai anggota tidak bisa menyimpan atau meminjam uang dari koperasi simpan pinjam (Padamu, 2016).

Berkaitan dengan hal ini, Kementerian koperasi \& UKM dan BAPPENAS, bekerja sama dengan Bank Dunia, berupaya memetakan berbagai model usaha KSP dan USP yang 
ada saat ini. Keberhasilan perusahaan sangat ditentukan oleh sumber daya manusia yang ada didalamnya.Oleh karena itu perusahaan harus mampu meningkatkan kinerja sumber daya manusianya. Kinerja adalah hasil kerja secara kualitas dan kuantitas yang dicapai oleh seorang pegawai dalam melaksanakan tugasnya sesuai dengan tanggung jawab yang diberikan kepadanya. (Prabu, 2009). Kinerja karyawan harus terus dipelihara dan ditingkatkan, salah satu caranya dengan penerapan Reward dan Punishment. Penghargaan (Reward) adalah sebuah bentuk apresiasi kepada suatu prestasi tertentu yang diberikan, baik oleh dan dari perorangan ataupun suatu lembaga yang biasanya diberikan dalam bentuk material atau ucapan (Fourthing, 2012).

Dalam organisasi ada istilah insentif, yang merupakan suatu penghargaan dalam bentuk material ataupun non material yang diberikan oleh pihak pimpinan organisasi kepada karyawan sebagai landasan motivasi. Hukuman (Punishment) adalah sebuah cara untuk mengarahkan sebuah tingkah laku agar sesuai dengan tingkah laku yang berlaku secara umum. Dalam hal ini, hukuman diberikan ketika sebuah tingkah laku yang tidak diharapkan ditampilkan oleh orang bersangkutan tidak memberikan respon atau tidak menampilkan sebuah tingkah laku yang diharapkan. (Fourthing, 2012). Dalam hal ini jika aturan dan hukum dalam suatu organisasi tidak berjalan dengan baik maka akan terjadi konflik kepentingan baik antar individu maupun organisasi. Koperasi Simpan Pinjam (KSP) BALOTA berpusat di Makale Kab. Tana Toraja, Prov.Sulsel, didirikan pada 1 Mei 1941 dengan nama Bank Cooperatie simpanan dan pinjaman bagi bangsa Boemipoetra Toradja. Koperasi ini dibangun sebagai bentuk keperihatinan terhadap maraknya praktik lintah darat oleh orang toraja sendiri dengan bunga yang amat mencekik leher orang miskin

Permasalahan yang sering terjadi dalam perusahaan KSP BALOTA dapat mengurangi tingkat kinerja karyawan, seperti tidak adanya pemberian penghargaan (Reward) kepada karyawan yang berprestasi dan permasalahan lainnya kurangnya pemberian Punishment atau hukuman kepada karyawan yang malas dan lalai dalam bekerja. Karena hal itu akan menyebabkan kinerja karyawan terganggu.Dengan adanya pemberianReward dan Punishmentyang dapat meningkatkan Produktifitasnya dalam bekerja dan karyawan yang semakin produktif akan meningkatkan laba perusahaan dan juga meningkatkan kesejahteraan karyawannya. Selain Rewardmemberikan Punishment atau hukuman kepada karyawan yang sesuai dengan kesalahan yang dilakukan oleh karyawan tersebut. Agar apa yang diharapkan akan meningkatkan kinerja karyawan tersebut dan tidak akan terjadi mengulangi kesalahannya lagi. Dengan permasalahan tersebut di atas penulis menganggap begitu penting untuk membahas bagaimana kinerja karyawan setelah mendapat Reward dan Punishment dari perusahaan tempat mereka bekerja. Oleh karena itu penulis akan berusaha mewujudkandalam karya tulis ini dengan judul, Pengaruh Reward dan Punishment terhadap kinerja karyawan pada KSP BALOTA Kota Palopo. 


\section{METODE PENELITIAN}

Penelitian ini dilaksanakan pada Koperasi Simpan Pinjam (KSP) BALOTA. Teknik pengumpulan data menggunakan observasi, kuesioner dan wawancara. Jenis data yang digunakan yaitu data kualitatif dan kuantitatif, sumber data yaitu data primer dan data sekunder. Teknik analisis data yang digunakan yaitu analisis deskriptif, uji validitas dan reliabilitas dan regresi linear berganda untuk menjawab hipotesis.

\section{HASIL DAN PEMBAHASAN}

\section{Hasil penelitian}

Tabel 1. Analisis Varians

ANOVA $^{\mathrm{a}}$

\begin{tabular}{|c|c|c|c|c|c|}
\hline Model & $\begin{array}{l}\text { Sum of } \\
\text { Squares }\end{array}$ & Df & $\begin{array}{l}\text { Mean } \\
\text { Square }\end{array}$ & $\mathrm{F}$ & Sig. \\
\hline 1 Regression & 734.243 & 2 & 367.122 & 175.771 & $.000^{\mathrm{b}}$ \\
\hline Residual & 35.507 & 17 & 2.089 & & \\
\hline Total & 769.750 & 19 & & & \\
\hline
\end{tabular}

a. Dependent Variable: Kinerja Karyawan

b. Predictors: (Constant), Punishment, Reward

Dari tabel di atas diketahui bahwa nilai $F_{\text {hitung }}$ sebesar 175.771 artinya $F_{h i t u n g}$ lebih besar daripada nilai $F_{\text {tabel }}$ 3,59 dengan taraf kepercayaan 95\%. Dengan demikian dapat dikatakan secara keseluruhan bahwa Reward (X1) dan Punishment(X2) berpengaruh signifikan terhadap kinerja karyawan KSP BALOTA Kota Palopo (Y).

Tabel 2. Analisis regresi

\section{Coefficients $^{\mathrm{a}}$}

\begin{tabular}{|c|c|c|c|c|c|c|}
\hline \multirow{2}{*}{\multicolumn{2}{|c|}{ Model }} & \multicolumn{2}{|c|}{$\begin{array}{l}\text { Unstandardized } \\
\text { Coefficients }\end{array}$} & \multirow{2}{*}{$\begin{array}{c}\text { Standardized } \\
\text { Coefficients }\end{array}$} & \multirow[b]{2}{*}{$\mathrm{T}$} & \multirow[b]{2}{*}{ Sig. } \\
\hline & & $\mathrm{B}$ & Std. Error & & & \\
\hline & (Constant) & 7.426 & 3.204 & & 2.318 & .033 \\
\hline & $R E W A R D(\mathrm{X} 1)$ & .671 & .218 & .578 & 3.086 & .007 \\
\hline & PUNISHMENT (X2) & .460 & .211 & .408 & 2.178 & .044 \\
\hline
\end{tabular}

a. Dependent Variable: KINERJA KARYAWAN

Diperoleh persamaan yaitu:

$$
\mathrm{Y}=(7.426)+(0,671) \mathrm{X} 1+(0,460) \mathrm{X} 2+\mathrm{e}
$$

Persamaan analisis regresi berganda dapat dijelaskan sebagai berikut:

a) Konstanta sebesar 7.426 artinya jika variabel Reward (X1) dan Punishment (X2) adalah (nol) maka Kinerja karyawan nilainya adalah 7.426 dengan asumsi variabel-variabel lain yang dapat mempengaruhi Kinerja Karyawan dianggap tetap.

b) Keofisien regresi variabel Reward 0,671 manyatakan bahwa setiap penambahan variabel Reward sebesar 1 satuan, maka terjadi kenaikan kinerja karyawan dengan asumsi yang bernilai tetap. 
c) Keofisien regresi variabel Punishment 0,460 mengatakan bahwa setiap pemandangan variabel Punishment sebesar 1 satuanmaka terjadi penurunan kinerja karyawan dengan asumsi yang bernilai tetap.

Hasil analisis secara parsial berdasarkan pada Tabel 2 dapat dijelaskan yaitu sebagai berikut:

a) Pada tabel terlihat bahwa variabel Reward (X1) berpengaruh signifikan terhadap Kinerja Karyawan KSP BALOTA Kota Palopo (Y). Hal ini ditunjukkan oleh nilai $\mathrm{T}_{\text {hitung }}$ (3.086)

$>\mathrm{T}_{\text {tabel }}(2.110)$ dengan tingkat kerpercayaan 95\%.

b) Pada tabel terlihat bahwa variabel Punishment (X2) juga berpengaruh signifikan terhadap Kinerja Karyawan KSP BALOTA Kota Palopo (Y). Hal ini ditunjukan oleh nilai $\mathrm{T}_{\text {hitung }}$ $(2.178)>\mathrm{T}_{\text {tabel }}(2.110)$ dengan tingkat kepercayaan 95\%.

\section{Pembahasan}

\section{Pengaruh Reward Terhadap Kinerja Karyawan}

Reward bisa diartikan sebagai ganjaran, hadiah, penghargaan atau imbalan, sama seperti pernyataan Moorhead \& Griffin (2013) yang menyatakan Reward atau penghargaan meliputi banyak dari perangsang yang disediakan oleh organisasi untuk karyawan sebagai bagian dari kontrak psikologis. Salah satu fungsi Reward adalah untuk digunakan sebagai perangsang terhadap para karyawan agar mampu berkinerja dengan maksimal, sesuai dengan tujuan Reward yang dinyatakan oleh Ivancevich (2000) dimana salah satu tujuan dari Reward adalah untuk memotivasi karyawan untuk mencapai tingkat kinerja yang tinggi. Hasil penelitian mengenai pengaruh Reward terhadap kinerja karyawan ini menunjukkan adanya pengaruh yang signifikan dari Reward terhadap kinerja karyawan di KSP BALOTA Kota Palopo dengan nilai signifikan sebesar 0,000 yang lebih kecil dari nilai level of significant $(0,005)$, yang artinya H1 diterima dan H0 ditolak. Berdasarkan hasil analisis regresi, terlihat bahwa pemberian Reward berpengaruh terhadap tingkat kinerja karyawan. Dimana variabel Reward mempunyai koefisien regresi positif sebesar 0,671 yang berarti Reward memiliki hubungan positif dengan kinerja.

Sistem Reward yang diterapkan KSP BALOTA Kota palopo saat ini seperti sistem bonus berdasarkan kinerja KSP BALOTA ataupun sistem promosi bagi individu sudah berjalan dan tersalurkan dengan baik sehingga berhasil mempengaruhi tingkat kinerja karyawannya. Dengan Reward yang sudah tertata dan tersalurkan dengan baik kepada karyawan, maka Reward tersebut mampu memotivasi para karyawan untuk berkinerja secara maksimal. Hasil tersebut sesuai dengan pernyataan Ivancevich (2000) dimana program Reward memiliki 3 tujuan utama, dimana salah satunya adalah untuk memotivasi karyawan untuk mencapai tingkat kinerja yang tinggi. Hal ini didukung dengan penelitian Irawati (2016) yang menemukan bahwa Reward mempengaruhi kinerja karyawan secara signifikan. Kemudian dilanjutkan oleh Sugihen dan Widyaningsih (2017) yang dalam penelitiannya menemukan indikasi adanya hubungan yang kuat antara Reward terhadap kinerja karyawan. Selanjutnya Hidayat (2018) dalam penelitiannya juga menemukan adanya pengaruh antara Reward terhadap kinerja karyawan. 


\section{Pengaruh Punishment Terhadap Kinerja Karyawan}

Punishment atau hukuman merupakan konsekuensi yang tidak menyenangkan atau tidak diinginkan sebagai hasil dari dilakukannya perilaku tertentu (Ivancevich, 2000). Penerapan Punishment secara tepat dan bijak dapat membantu karyawan untuk mengintrospeksi diri kemudian mempelajari dan memperbaiki kinerjanya ketika mereka melakukan kesalahan, sesuai dengan pernyataan Irawati (2016) yang menyatakan jika Punishment merupakan suatu reinforcement atau suatu bentuk yang negatif, tetapi apabila Punishment diberikan secara tepat dan bijak dapat menjadi alat perangsang karyawan untuk meningkatkan kinerjanya. Hasil penelitian mengenai pengaruh Punishment terhadap kinerja karyawan ini menunjukkan adanya pengaruh yang signifikan dari Punishment terhadap kinerja karyawan di KSP BALOTA Kota Palopo dengan nilai signifikansi sebesar 0,000 yang lebih kecil dari nilai level of significant $(0,005)$, yang artinya $\mathrm{H} 1$ diterima dan $\mathrm{H} 0$ ditolak. Berdasarkan hasil analisis regresi, terlihat bahwa pemberian Punishment berpengaruh terhadap tingkat kinerja karyawan. Dimana variabel Punishment mempunyai koefisien regresi positif sebesar 0,460 yang berarti Punishment memiliki hubungan positif dengan kinerja.

Sistem Punishment yang diterapkan KSP BALOTA Kota Palopo saat ini terdiri dari beberapa tahapan seperti peringatan lisan, peringatan tertulis, dan Surat Peringatan (SP) mulai dari SP I tanpa skorsing, SP II dengan skorsing, sampai dengan SP III berupa pemberhentian kerja. Keseluruhan sistem Punishment tersebut telah berjalan dan diterapkan secara tepat dan bijak sehingga didapat efek yang didapat bukanlah negatif, melainkan efek positif berupa peningkatan kinerja karyawan. Hasil tersebut sesuai dengan penelitian Sugihen dan Widyaningsih (2017) yang menemukan bahwa Punishment dibutuhkan untun memotivasi pegawai dalam meningkatkan kinerjanya, artinya Punishment berpengaruh positif terhadap kinerja karyawan. Kemudian dilanjutkan oleh Hidayat (2018) yang dalam penelitiannya menemukan bahwa Punishment berpengaruh signifikan terhadap kinerja karyawan.

Selanjutnya Hani (2014) dalam penelitiannya juga menemukan bahwa Punishment berpengaruh signifikan terhadap kinerja karyawan.

\section{SIMPULAN DAN SARAN}

\section{Simpulan}

Berdasarkan hasil analisis dan pembahasan diatas, maka dapat ditarik beberapa kesimpulan dari hasil penelitian ini, yaitu:

1. Berdasarkan hasil analisis regresi, terlihat bahwa pemberian Reward berpengaruh terhadap tingkat kinerja karyawan. Dimana variabel Reward mempunyai koefisien regresi positif sebesar 0,671 yang berarti Reward memiliki hubungan positif dengan kinerja.

2. Dan hasil analisis regresi, terlihat bahwa pemberian Punishment berpengaruh terhadap tingkat kinerja karyawan. Dimana variabel Punishment mempunyai koefisien regresi positif sebesar 0,460 yang berarti Punishment memiliki hubungan positif dengan kinerja.

3. Dari kedua variabel independen yang paling mempengaruhi variabel dependen yaitu Reward karenavariabel Rewardmempunyai koefisien regresi lebih tinggiyaitu 0,671 sedangkan Punishment mempunyai koefisien regresi lebih kecil yaitu 0,460. Jadi dapat 
disimpulkan Reward lebih berpengaruh terhadap kinerja karyawan dibandingkan Punishment.

\section{Saran}

Berdasarkan hasil dari penelitian ini, penulis dapat menyampaikan beberapa saran bagi KSP BALOTA Kota Palopo yaitu:

1. Sistem Reward yang diterapkan oleh pihak KSP BALOTA Kota Palopo harus juga diterapkan untuk karyawan agar karyawan dapat motivasi untuk lebih meningkatkan produktivitasnya dalam berkerja.

2. Sistem Punishment yang diterapkan oleh pihak KSP BALOTA Kota Palopo walaupun belum terlalu berpengaruh terhadap kinerja karyawan, maka harus lebih dit ' ' tkan lagi agar karyawan yang dapat merugikan perusahaantidak lagi membuat kesalanan yang sama dan mendapatkan pembelajaran dari Punishment yang diterapkan di perusahaan dan dapat memotivasi karyawan agar dapat bekerja dengan disiplin dan lebih baik lagi untuk perusahaan.

\section{DAFTAR PUSTAKA}

Fourthing. 2012. Reward and Punishment. [Diunduh 2018 okt 02]. Tersedia Pada Https://Fourthing-wordpresscom.cdn.ampproject.

Hasibuan M.2012. Manajemen Sumber Daya Manusia, Edisi Revisi, Cetakan Keenam Belas.PT.Bumi Aksara: Jakarta.

Hani T, Handoko. 2000. Manajemen Personalia dan Sumber Daya Manusia, Edisi kedua Yogyakarta: BPFE Yogyakarta.

Hidayat F . 2018. Pengaruh Reward dan Punishment Terhadap Kinerja Karyawan dengan Disiplin Kerja Sebagai Variabel Intervening di Waroeng Spesial Sambal Yogyakarta. [Skripsi]. Fakultas Ekonomi slam Universitas Islam Indonesia.

Hani U, Maula. 2014. Pengaruh Reward, Punishment, Tingkat Absensi dan Turnover Intentions Terhadap Kinerja Karyawan Pada PT.Sharp Electronics Indonesia Jamber. [Skripsi]. Fakultas Ekonomi Universitas Jamber.

Irawanti A. 2016. Pengaruh Pemberian Reward dan Punishment Terhadap Kinerja Karyawan

(Studi Kasus Pada BMT Lima satu sejahtera Jerapa). Fakutas Ekonomi dan Bisnis Islam Negeri Walisongo Semarang.

Mangkunegara. 2011. Sumber Daya Manausia.PT. Remaja Rosda Karya: Bandung

Mangkunegara, Anwar Prabu. 2002. Manajemen Sumber Daya Manusia. Remaja Rosdakarya. Bandung

Nitisemito, Alex. 2001. Manajemen Personalia. Bandung: Penerbit Bumi Askara.

Nurlaila, 2010. Manajemen Sumber Daya Manusia I. Penerbit LepKhair.

Nurmiyati E. 2011.Hubungan Pemberian Reward dan Punishment Dengan Kinerja Karyawan Pada BPRS Harta Insan Karimah. [Skripsi].FakultasSyariah dan Hukum UIN Syarif Hidayatullah.

Ningsih W. 2017. PengaruhReward dan Punishment Terhadap Kinerja Karyawan PT. Kereta Api Indonesia (KAI) Persero DAOP V Purwokerto Stasiun Kutoarjo.Fakultas Ekonomi Universitas Muhammadiyah Purworejo.

Padamu, A. 2016. Pengertian Koperasi Simpan Pinjam. [Diunduh 2018 okt 01]. Tersedia pada, Https://www.padamu.net/pengertian-koperasi-simpan pinjam. 
Prasetyo A, Febrianti S. 2014. Pengaruh Reward dan Punishment Terhadap Motivasi Kerja Serta Dampaknya Terhadap Kinerja (studi pada karyawan PT.Panin Bank Tbk. Area Mikro Jombang). Jurnal Administrasi Bisnis. 12(1) : 1-9.

Prawirosentono, Suryadi. 1999. Kebijakan Kinerja Karyawan. Yogyakarta: BBFE.

Purwanto. 2007. Instrumen Penelitian Sosial dan Pendidikan. Yogyakarta: Pustaka Belajar.

Rivai. 2011. Manajemen Sumber Daya manusia Untuk Perusahaan: dari Teori ke Praktik .Jakarta: Raja Grafindo Persada.

Sitorus D. 2013. Mengenal Keragaman Model Koperasi Simpan Pinjam di Indonesia, Catatan Teknis, KPS Balo' Toraja. [Diunduh 2018 Okt 07] Tersedia pada: Http://www.imfea.or.id/images/e-book/1 Model\%20Bisnis \%20balota.pdf.

Sugihen D, Paul. 2017. Pengaruh Reward dan Punishment Terhadap Motivasi Kerja Karyawan PT. Pancaran Subur Makmur Distributor Produk Nestle Medan. Fakultas Ekonomi dan Bisnis Universitas Sumatera Utara Medan. 